\title{
Pregnancy associated plasma protein A: an early predictor of fetal growth restriction
}

\author{
Pavan Bhargava Chandramohan*, Sarita Agrawal, Chandrashekhar Shrivastava, \\ Sarita Rajbhar, Prasanta Nayak, Vinita Singh
}

Department of Obstetrics and Gynaecology, All India Institute of Medical Sciences, Greater Eastern Road, Raipur, Chhattisgarh, India

Received: 28 September 2021

Accepted: 28 October 2021

\section{*Correspondence:}

Dr. Pavan Bhargava Chandramohan,

E-mail: swastikbcp@gmail.com

Copyright: ( $\odot$ the author(s), publisher and licensee Medip Academy. This is an open-access article distributed under the terms of the Creative Commons Attribution Non-Commercial License, which permits unrestricted non-commercial use, distribution, and reproduction in any medium, provided the original work is properly cited.

\begin{abstract}
Background: The aim of our study was to determine the association of low levels of pregnancy associated plasma protein-A (PAPP-A) levels estimated at 11-13+6 weeks of gestation with fetal growth restriction (FGR).

Methods: A prospective observational study of a total of 203 pregnant women with PAPP-A levels were followed up and the outcome data were collected at childbirth.

Results: The incidence of FGR was 7.3\%. A significant association was found between low levels of PAPP-A MoM $(\leq 0.49)$ with FGR $(p=0.000)$ with unadjusted odds ratio of 11.6. At PAPP-A multiples of median $(\mathrm{MoM}) \leq 0.49$, FGR had a median $(\mathrm{Q} 1, \mathrm{Q} 3)$ of $0.46(0.42,1.54)$ versus $1.87(0.59,3.11)$ which was statistically significant $(\mathrm{p}=0.05)$ with moderate strength of prediction [minus $0.58(95 \% \mathrm{CI}$, minus 1.113 , minus 0.055$), \mathrm{p}=0.03$ ]. At the cut-off considered in our study i.e., $\leq 0.49 \mathrm{MoM}$, sensitivity, specificity, positive predictive value (PPV) and negative predictive value (NPV) were $73 \%, 81 \%, 23 \%$, and $97 \%$ respectively with a positive LR of 3.82 and negative LR of 0.32 . Karl Pearson's correlation showed positive correlation $(\mathrm{r}=0.308, \mathrm{p}<0.001)$ between PAPP-A MoM and birthweight and showed that for every unit increase in PAPP-A MoM, birthweight increased by 0.082 times (approximately 90 gm). We also found an association of low PAPP-A with pre-eclampsia, preterm delivery and increased caesarean delivery births.

Conclusions: We conclude that low PAPP-A MoM levels are good reflectors of placental function and adverse outcomes. PAPP-A, a part of the dual marker, may be extrapolated for suspecting FGR. This could guide in instituting appropriate feto-maternal surveillance.
\end{abstract}

Keywords: FGR, Pregnancy associated plasma protein-A, Early marker

\section{INTRODUCTION}

The female physiology undergoes miraculous transformations to make everything as conducive as needed for the growing fetus. FGR, a relatively newer terminology that refers to intrauterine growth restriction, is defined as a failure (of a fetus) to achieve the endorsed growth potential. This restriction is associated with (signs of) abnormal feto-placental function and poorer perinatal outcome. ${ }^{1}$ Institutions/obstetric practitioners mostly rely on the cut-offs of various ultrasonographic parameters for designating a fetus as one with FGR. However, a consensus regarding terminology, etiology, and diagnostic criteria for FGR remains to be fully understood. ${ }^{2}$

Detection and accurate prediction of FGR remains to be a challenging task. Various methods are used for antenatal recognition of FGR. Used individually or in conjunction, depending on the resource-setting, these may be-(a) clinical examination, (b) ultrasonography, (c) birth weight charts and/or (d) serum biomarkers

Pregnancy-associated plasma protein-A' (PAPP-A) is a product of the multinucleated syncytiotrophoblasts of the 
placenta. PAPP-A acts locally to enhance the bioavailability of insulin-like growth factor (IGF) by cleaving the inhibitors, IGF-binding protein-4 and $-5 .^{3-5}$ Which causes a significant decrease in its affinity for IGF molecules. IGF, known to be anti-apoptotic and mitogenic, is important for the growth of almost all types of cells/tissue. ${ }^{6,7}$ IGF also has a pivotal role in placental development and spiral artery remodeling is linked to its stimulation of cytotrophoblast proliferation and migration of extra villous trophoblast in the first trimester. ${ }^{8}$ PAPP-A with beta human chorionic gonadotropin, as dual marker, is presently a well-established down syndrome marker and is recommended for screening programs of chromosomal abnormalities. Systemic reviews and meta-analyses, although limited in number, have concluded that low maternal serum PAPP-A in the first trimester has an association with adverse pregnancy outcome(s) and particularly so if the levels are very low. ${ }^{9-16}$ Preventive and/or early diagnosis may thus lead to greater surveillance and help in minimizing the impact of adverse outcomes. This is of particular importance to resource limited demography such as ours in India.

PAPP-A as an early marker of FGR is not yet established in practice due to insufficient evidence. We studied PAPP$\mathrm{A}$ in this regard on a Central Indian population.

\section{METHODS}

This prospective observational study was carried out in the department of obstetrics and gynecology, All India institute of medical sciences, Raipur, Chhattisgarh, India, after obtaining clearance from the institute ethics committee. The aim of our study was to determine the association of low levels of maternal serum pregnancy associated plasma protein-A (PAPP-A) levels estimated at 11-13+6 weeks of gestation with FGR.

All women with singleton pregnancy who underwent firsttrimester screening between 11-13+6 weeks were identified and evaluated as per standard antenatal evaluation protocol of the Institute. Inclusion criteria were all women attending antenatal clinic with singleton pregnancy, having PAPP-A report done between 11 and $13+6$ weeks of gestation and willing to participate in the study. We excluded those pregnant women with multiple pregnancy, congenital anomalies, known chronic diseases like diabetes mellitus, thyroid dysfunction, chronic hypertension, collagen vascular diseases, liver and renal disorders. Those women who satisfied the study criteria were recruited and followed up in the antenatal clinic. At recruitment, demographic details, and exact gestational age, determined by crown-rump length, were recorded. At each visit, detailed history-taking and clinical examination were performed and the reports of investigations relevant to that particular gestational age were noted. Ultrasonographic findings of dating scan, early anomaly scan (11 to $13+6$ weeks), targeted imaging for fetal anomalies (at 18 to 22 weeks) and third trimester growth scans with doppler studies were noted. Additional investigations and adversities, if any, were recorded. At delivery, gestational age at birth, mode of delivery, the sex of the newborn and birthweight, and neonatal intensive care unit admission if at all, were noted.

The primary outcome variable, FGR, was defined as per the Delphi consensus criteria. PAPP-A MoM $\leq 0.49$ was considered as cut-off in our study.

Data was compiled on the Microsoft excel version 15.0. Descriptive and categorical data were analyzed using IBM SPSS statistical software version 23.0. Tests of normality namely, Kolmogorov-Smirnov and Shapiro-Wilk tests, were performed to assess normality of distribution. Qualitative data were analyzed by Chi-square and Fisher exact tests and Categorical data were analyzed by MannWhitney $U$ test. Odds ratio was applied to obtain the strength of association. Simple logistic regression estimates of PAPP-A in predicting FGR was obtained. Receiver operator characteristics (ROC) was used for analysis of the area under the curve (AUC) for PAPP-A. Karl Pearson's correlation for PAPP-A MoM with birthweight was applied. Simple linear regression equation for prediction of birthweight from PAPP-A was obtained. $\mathrm{P}=0.05$ was considered significant.

\section{RESULTS}

The data of 203 antenatal women were analyzed. The initial recruitment and the final enrolment of subjects is shown in the STROBE diagram (Figure 1).

\begin{tabular}{|l|l|}
\hline RECRUITMENT & \multicolumn{1}{|c|}{$\begin{array}{l}\text { ASSESSMENT FOR ELIGIBILTY, }(\mathrm{n}=226) \\
\text { Chronic hypertension- } 5 \\
\text { Diabetes mellitus- 4 } \\
\text { Fetal anomaly- } \\
\text { Multiple endocrinopathies- } 1 \\
\text { Nephrotic syndrome- } 1\end{array}$} \\
\hline DATA COLLECTION & INCLUDED IN THE STUDY, (n=211) \\
\hline FOLLOW-UP & LOST TO FOLLOW-UP, (n=4) \\
\hline FOLLOW-UP AND BIRTH OUTCOME RECORDED \\
(n=207)
\end{tabular}

Figure 1: STROBE diagram of study subject inclusions and exclusions with reasons.

Incidence of FGR was 7.3\%. The mean maternal age in our study was $24.8 \pm 3.61$ years. The maximum number of women i.e., $120(59.11 \%)$ were urban residents and 83 $(40.89 \%)$ women were rural residents. The $54.2 \%$ of women were primigravida. Although the mean BMI was $24.12 \pm 3.13 \mathrm{~kg} / \mathrm{m}^{2}$, max. no. of women i.e., $68(33.5 \%)$ belonged to obese category (as determined by WHO 
classification of BMI for South Asians/Indians) which was a surprising observation. In study, 7 (3.45\%) women had conceived by assisted reproductive techniques. The incidence of FGR was found to be higher in urban residents [OR-2.5 (95\% CI, 1.11-5.63), p=0.023] and invitro fertilization/ intra-uterine insemination (IVF/IUI) conceptions [OR-6.58 (95\% CI, 1.40-30.81), p=0.007].

PAPP-A levels were not found to be significantly different in women belonging to different age groups, literacy status, socio-economic status, residential status, gravidity or different BMI groups. None of the women in the study was a smoker. Therefore, it may be inferred that these factors have had no confounding effect on PAPP-A values in predicting FGR. $29.5 \%$ women were delivered by Caesarean section. In the study, out of 203 births, 106 $(52.21 \%)$ were female babies and $97(47.78 \%)$ were male babies. $25 \%$ of neonates that needed NICU admission were born to women with PAPP-A MoM $\geq 0.49$. Figure 2 shows the distribution of FGR and PAPP-A.

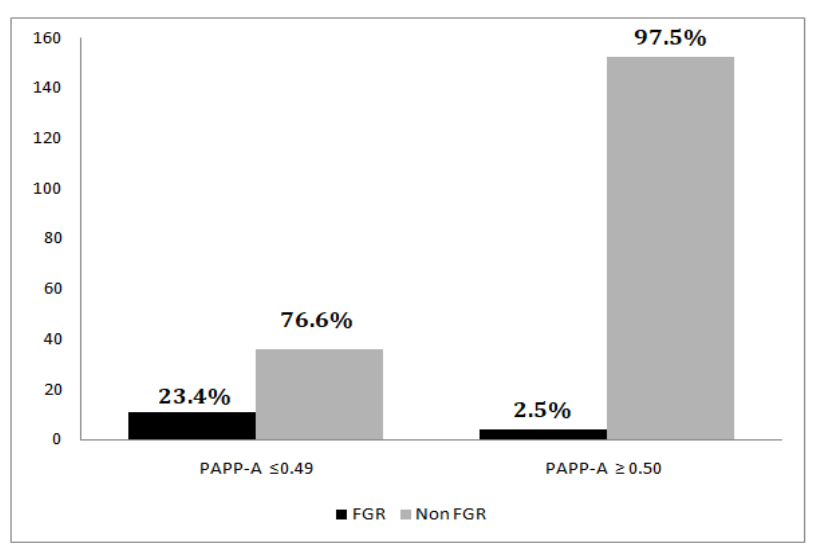

Figure 2: Distribution of FGR and PAPP-A among study subjects.

We found a significant association between low levels of PAPP-A MoM with FGR ( $\mathrm{p}=0.000$ ) with unadjusted OR 11.6 (95\% CI 3.494, 38.576). At PAPP-A MoM $\leq 0.49$, FGR had a median (Q1, Q3) of $0.46(0.42,1.54)$ vs 1.87 $(0.59,3.11)$ which was statistically significant $(\mathrm{p}=0.05)$ and showed moderate strength of prediction $[-0.58(95 \%$ CI 1.113, 0.055), $\mathrm{p}=0.03$ ].

Area under the ROC curve (Figure 3) showed an optimal cut-off of 0.52 for prediction of FGR of PAPP-A MoM, with $80.9 \%$ sensitivity and $73.3 \%$ specificity. At the cutoff considered in our study i.e., 0.49 MoM, sensitivity, specificity, PPV and NPV were $73 \%, 81 \%, 23 \%$, and $97 \%$ respectively with a positive LR of 3.82 and negative LR of 0.32 .

Karl Pearson's correlation (Figure 4) showed positive correlation $(\mathrm{r}=0.308, \mathrm{p}<0.001)$ between PAPP-A MoM and birthweight and showed that for every unit increase in PAPP-A MoM, birthweight increased by 0.082 times (approx. $90 \mathrm{gm}$ ).

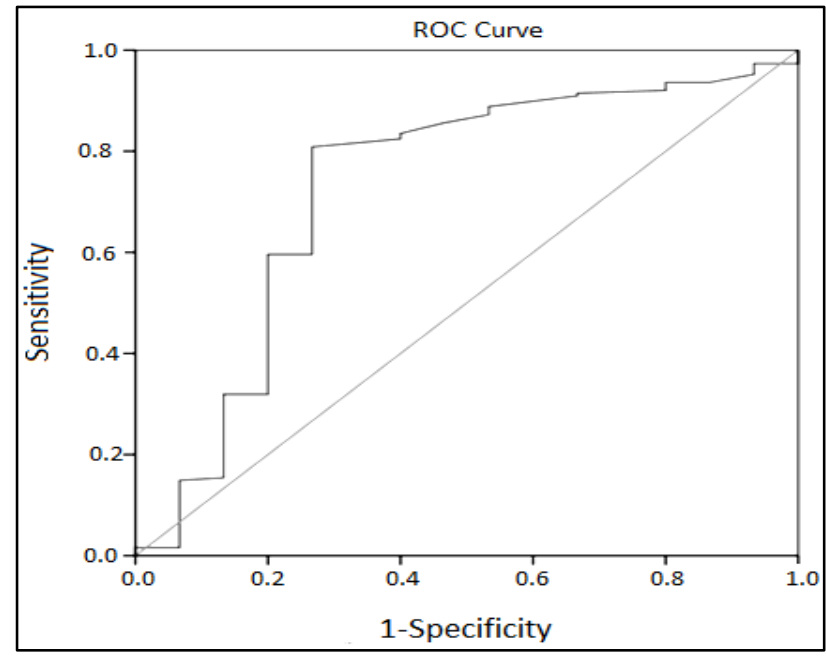

Figure 3: Area under the ROC curve.

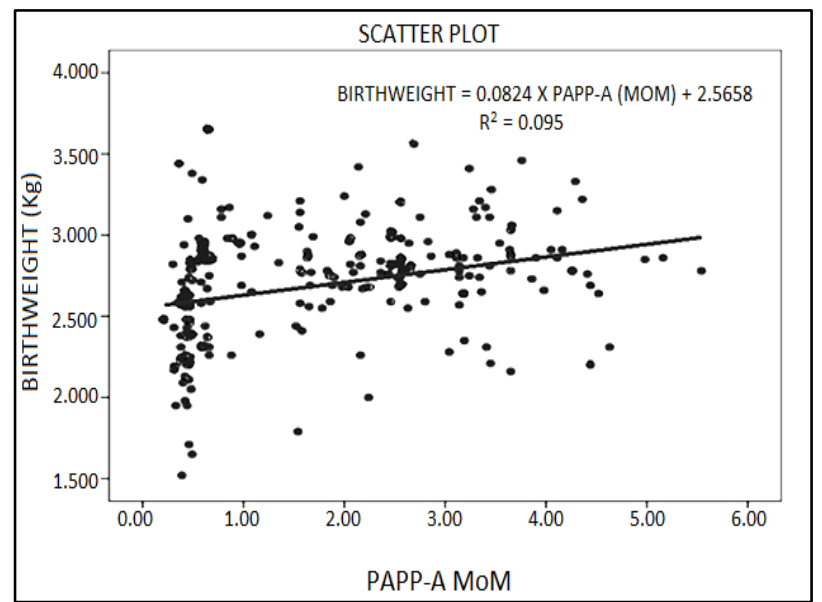

Figure 4: Scatter plot of Karl Pearson's correlation between PAPP-A MoM and birthweight.

In addition, we made the observations-low levels of PAPPA were found to be significantly associated with preeclampsia [incidence-11.33\%, OR 4.72 (95\% CI 1.453, $15.342), \mathrm{p}=0.016 \mathrm{~F}$ ] oligohydramnios [incidence- $10.83 \%$, OR-5.02 (95\% CI 1.539, 16.426), $\mathrm{p}=0.01]$ preterm deliveries [incidence-5.9\%, OR-8.18 (95\% CI 2.130, 31.428), $\mathrm{p}=0.006$ ], caesarean deliveries [incidence29.5\%, OR-5.52 (95\% CI 1.7988, 16.938), $\mathrm{p}=0.002]$ and NICU admissions [incidence-7.8\%, OR-11.86 (95\% CI $3.525,39.928), \mathrm{p}=0.0002]$.

\section{DISCUSSION}

FGR is known to cause several feto-maternal adverse consequences. ${ }^{1}$ We decided to use a cut-off of $\leq 0.49$ to define low PAPP-A, conforming to consensus as per literature. Although a value less than $0.5 \mathrm{MOM}$ is considered low, there exists no set definition as to what value defines low PAPP-A MoM. Different authors have used different cut-offs in their studies (Table 1), but the outcome findings suggest a similar trend. ${ }^{17-20}$ 
Table 1: Summary of studies of FGR and PAPP-A.

\begin{tabular}{|c|c|c|c|c|c|c|}
\hline Authors & $\begin{array}{l}\text { Participant } \\
\text { numbers }\end{array}$ & $\begin{array}{l}\text { Incidence of } \\
\text { FGR }(\%)\end{array}$ & $\begin{array}{l}\text { PAPP-A, MoM } \\
\text { cut-off }\end{array}$ & $\begin{array}{l}\text { Sensitivity } \\
(\%)\end{array}$ & PPV $(\%)$ & OR/RR \\
\hline Present study & 203 & 7.3 & 0.5 & 73 & 23 & 11.6 \\
\hline Inan et $a^{17}$ & 162 & 8.6 & 0.64 & 71.43 & 17.2 & \\
\hline Gupta et al ${ }^{18}$ & 130 & 21.54 & & & & 7.83 \\
\hline Sovio et al ${ }^{19}$ & 1891 & & 0.74 & & & 6.59 \\
\hline Yaron et $\mathrm{al}^{20}$ & 1622 & 3 & $0.25,0.5$ & & & $3.12,3.30$ \\
\hline
\end{tabular}

FGR-Fetal growth restriction, MoM-Multiples of median, OR-Odds ratio, PAPP A- pregnancy associated plasma protein-A, PPV-Positive predictive value, RR-Relative risk.

The incidence of FGR in our study was $7.3 \%$. Inan et al found the FGR incidence of $8.6 \%$ in their study of 162 women. ${ }^{17}$ A case control study of 264 women by Lavanya et al conducted in India, found an incidence of $6.8 \% .^{20}$ Studies show that the incidence of FGR is significant amongst different population settings. ${ }^{17,18,20}$

We found a significant association between low levels of PAPP-A MoM with FGR. ( $\mathrm{p}=0.000)$ with unadjusted OR 11.6 (95\% CI, 3.494-38.576). At PAPP-A MoM $\leq 0.49$, FGR had a median (Q1, Q3) of $0.46(0.42,1.54)$ vs 1.87 $(0.59,3.11)$ which was statistically significant $(\mathrm{p}=0.05)$ and showed moderate strength of prediction $[-0.58(95 \%$ CI, -1.113, -0.055), $\mathrm{p}=0.03]$. Lavanya et al found an association of low PAPP-A $(<0.5 \mathrm{MoM})$ with FGR [OR 33.46 (5.9-189.4)] while Gupta et al found an association with FGR [OR $7.837(2.485-24.711) \mathrm{p} \leq 0.0001] .^{18,22}$

At the cut-off considered in our study i.e., 0.49 MoM, sensitivity specificity, PPV and NPV were $73 \%, 81 \%$, $23 \%$, and $97 \%$ respectively with a positive LR of 3.82 and negative LR of 0.32 .

In their study, at a PAPP-A MoM cut-off of 0.64, Inan et al found that the sensitivity and PPV were respectively $71.43 \%$ and $17.2 \% .^{17}$ Studies found in literature have demonstrated reliably high sensitivity.

The most interesting observation of our study is of increase in birthweight by approximately $90 \mathrm{gm}$ per unit increase in PAPP-A MoM levels. Peterson et al in their retrospective cohort of 1391 women found an increase in birthweight by $119 \mathrm{gm}$ for every 1 unit increase of PAPP-A MoM. ${ }^{22}$ Summary of a few studies on FGR and PAPP-A (Table 1).

\section{Limitations}

The study is limited by small sample size but prospective study design and demonstration of predictive ability of PAPP-A are the strengths of our study.

The increasing birthweight per unit increase in PAPP-A MoM is a highlight.

\section{CONCLUSION}

FGR has drawn significant attention of health care providers and researchers, as there exists a possibility of reversing or blunting its consequences, especially when detected in early gestation. Incorporation of new analytes, such as PAPP-A, into health-care investigations demands allocation of funds which is a challenge in resource-limited set ups. However, cost effectiveness equations must be weighed against purported benefits of reduced morbidity/ mortality, that PAPP-A demonstrates in our study.

The following conclusions are drawn from our study. Low PAPP-A MoM levels are associated with FGR. At the cutoff of 0.49 , MoM we found $73 \%$ sensitivity, $81 \%$ specificity, 23\% PPV and 97\% NPV; and with every unit increase in PAPP-A MoM, birth weight is seen to be increased by about $90 \mathrm{gm}$.

It can be concluded that low PAPP-A MoM levels are good reflectors of placental function and may serve as good early predictor of fetal growth restriction.

\section{ACKNOWLEDGMENTS}

Authors would like to thank to all study subjects, and Dr. Pragyan Paramita Pradhan and Dr. Taru Shikha for their help in technical and material support.

\section{Funding: No funding sources}

Conflict of interest: None declared

Ethical approval: The study was approved by the Institutional Ethics Committee

\section{REFERENCES}

1. Figueras F, Gratacós E. Update on the diagnosis and classification of fetal growth restriction and proposal of a stage-based management protocol. Fetal Diagn Ther. 2014;36(2):86-98.

2. ACOG Practice Bulletin No. 204: Fetal Growth Restriction. Obstet Gynecol. 2019;133(2):e97-109.

3. Laursen LS, Overgaard MT, Soe R, Boldt HB, Sottrup-Jensen L, Giudice LC et al. Pregnancyassociated plasma protein-A (PAPP-A) cleaves insulin-like growth factor binding protein (IGFBP)-5 independent of IGF: implications for the mechanism of IGFBP-4 proteolysis by PAPP-A. FEBS letters. 2001;504(1-2):36-40.

4. Laursen LS, Kjaer-Sorensen K, Andersen MH, Oxvig C. Regulation of insulin-like growth factor (IGF) bioactivity by sequential proteolytic cleavage of IGF 
binding protein-4 and 5. Molecular endocrinol. 2007;21(5):1246-57.

5. Sun IY, Overgaard MT, Oxvig C, Giudice LC. Pregnancy-associated plasma protein A proteolytic activity is associated with the human placental trophoblast cell membrane. J clin endocrinol metabolism. 2002;87(11):5235-40

6. Jones JI, Clemmons DR. Insulin-like growth factors and their binding proteins: biological actions. Endocrine reviews. 1995;16(1):3-34.

7. Clemmons DR. Role of insulin-like growth factor binding proteins in controlling IGF actions. Molecular cellular endocrinol. 1998;140(1-2):19-24.

8. Sferruzzi-Perri AN, Owens JA, Pringle KG, Roberts CT. The neglected role of insulin like growth factors in the maternal circulation regulating fetal growth. J physiol. 2011;589(1):7-20.

9. Bischof P, DuBerg S, Herrmann W, Sizonenko PC. Pregnancy-associated plasma protein-A (PAPP-A) and hCG in early pregnancy. Bri $\mathrm{j}$ obstetr gynaecol.1981;88(10):973-5.

10. RCOG. The Investigation and Management of the Small-for-Gestational-Age Fetus. Greentop Guideline No. 31:RCOG. 2014.

11. Krantz D, Goetzl L, Simpson JL. Association of extreme first-trimester free human chorionic gonadotropin-beta, pregnancy-associated plasma protein $\mathrm{A}$, and nuchal translucency with intrauterine growth restriction and other adverse pregnancy outcomes. Am J Obstet Gynecol. 2004;191(4):14528. 4.

12. Pakniat H, Bahman A, Ansari IJ. The Relationship of Pregnancy-Associated Plasma Protein A and Human Chorionic Gonadotropin with Adverse Pregnancy Outcomes: A Prospective Study. Obstet Gynecol India. 2019;69:412.

13. Dugoff L, Hobbins JC, Malone FD, Porter TF, Luthy $\mathrm{D}$, Comstock $\mathrm{CH}$ et al. First trimester maternal serum PAPP-A and free-beta subunit human chorionic gonadotropin concentrations and nuchal translucency are associated with obstetric complications: a population-based screening study (the FASTER Trial). Am J Obstet Gynecol. 2004;191(4):1446-51.

14. Smith GC, Shah I, Crossley JA, Aitken DA, Pell JP, Nelson SM et al. Pregnancy associated plasma protein
A and alpha-fetoprotein and prediction of adverse perinatal outcome. Obstet Gynecol. 2006;107(1):1616.

15. Spencer CA, Allen VM, Flowerdew G, Dooley K, Dodds L. Low levels of maternal serum PAPP-A in early pregnancy and the risk of adverse outcomes. Prenat Diagn. 2008;28(11):1029-36

16. Morris RK, Cnossen JS, Langejans M, Robson SC, Kleijnen J, TerRiet $G$ et al. Serum screening with Down's syndrome markers to predict pre-eclampsia and small for gestational age: systematic review and meta-analysis. BMC pregnancy childbirth. 2008;8:33

17. Inan C, Varol FG, Erzincan SG, Uzun I, Sutcu H, Sayin CN. Use of prokineticin-1 (PROK1), pregnancy-associated plasma protein A (PAPP-A) and PROK1/PAPP-A ratio to predict adverse pregnancy outcomes in the first trimester: a prospective study. J Maternal-Fetal Neonatal Med. 2018;31:20:2685-92.

18. Gupta S, Goyal M, Verma D, Sharma A, Bharadwaj $\mathrm{N}$, Kabra $\mathrm{M}$ et al. Adverse pregnancy outcome in patients with low pregnancy-associated plasma protein-A: The Indian Experience. J Obstet Gynaecol Res. 2015;41:1003-8.

19. Sovio U, Smith G, Darcy A. First trimester PAPP-A and the risk of fetal growth restriction. Am J Obstet Gynecol. 2014;S112.

20. Yaron Y, Heifetz S, Ochshorn Y, Lehavi O, OrrUrtreger A. Decreased first trimester PAPP-A is a predictor of adverse pregnancy outcome. Prenat Diagn. 2002;22(9):778-82.

21. Lavanya T, Premalatha R, Thakkar NA, Jawahar L, Rajendran PK, Geethanjali E et al. The role of pregnancy associated plasma protein - A level in the first trimester of pregnancy and clinical outcome in an urban referral centre. Int J Reprod Contr Obstet Gynecol. 2019;8:3884-8.

22. Peterson SE, Simhan HN. First-trimester pregnancyassociated plasma protein A and subsequent abnormalities of fetal growth. Am J Obstet Gynecol. 2008;198(5):e43-5.

Cite this article as: Chandramohan $\mathrm{PB}$, Agrawal S, Shrivastava C, Rajbhar S, Nayak P, Singh V. Pregnancy associated plasma protein A: an early predictor of fetal growth restriction. Int J Reprod Contracept Obstet Gynecol 2021;10:4517-21. 